\title{
Lack of difference between malignant and accelerated hypertension
}

\author{
$M$ E K AHMED, J M WALKER, D G BEEVERS, M BEEVERS
}

\begin{abstract}
The clinical features and survival rates of 200 consecutive patients with malignant and accelerated hypertension admitted to a district hospital were investigated. Ninety five patients had bilateral haemorrhages and exudates and papilloedema (grade IV retinopathy) and 31 had bilateral haemorrhages and exudates with no papilloedema (grade III). A further 74 patients had bilateral retinopathy but failed to meet the criteria for grade IV or III and were investigated separately. No overall differences were found in survival when comparing the various grades of retinopathy. Cigarette smoking was significantly commoner only in grade IV patients compared with those with non-malignant hypertension matched for age, sex, and race. In patients with grade III retinopathy excess smoking was not statistically significant.
\end{abstract}

In conclusion, the clinical features and survival rate showed that malignant and accelerated hypertension are one and the same disease.

\section{Introduction}

There is no universally accepted definition of malignant hypertension. The histological hallmark is said to be fibrinoid necrosis of arterioles, ${ }^{1}$ but this feature is not completely specific as it is also seen in patients with hypertension and renal disease who do not have the ophthalmological features of exudative or haemorrhagic retinopathy.$^{2 \cdot 7}$ The presence of papilloedema has been claimed to be a sine qua non of malignant hypertension, ${ }^{7}$ and patients with retinal haemorrhages and exudates without papilloedema have been described as having "premalignant" or accelerated hypertension. ${ }^{8} \mathrm{By}$ contrast the World Health Organisation" and many other authors ${ }^{1011}$ have considered that the term malignant should be applied to cases of hypertension with bilateral haemorrhages and exudates, with or without papilloedema, representing Keith Wagener grades III and IV retinopathy. ${ }^{12}$ This confusion has led us to investigate the clinical features and survival rates of patients with both types of retinopathy to see whether the subdivision into grades III and IV is clinically useful.

We and at least three other groups have noted cigarette smoking to be commoner in patients with malignant hypertension than in control patients with non-malignant hypertension. ${ }^{13-16}$ We have, therefore, investigated the smoking habits of our patients with grades III and IV retinopathy separately, in comparison with a control group matched for age, sex, and race, to test whether excess smoking in patients with malignant hypertension is present in those with and without papilloedema.

\footnotetext{
University Department of Medicine, Dudley Road Hospital, Birmingham B18 7QH

M E K AHMED, MB, MRCP, research fellow

J M WALKER, MD, MRCP, research fellow

D G BEEVERS, MD, FRCP, reader in medicine

$M$ BEEVERS, SRN, research assistant

Correspondence to: Dr Beevers.
}

\section{Patients and methods}

The data from the hospital inpatient activity analysis for this hospital were used to identify all patients discharged with a diagnosis of malignant hypertension (International Classification of Diseases code 400) from 1960 to 1982. We were able to identify exactly 200 patients with hypertension who were considered to be in the malignant phase by the clinician at the time of discharge from hospital. The records of all patients were then examined.

Patients were classified into four groups based on the ophthalmological features recorded at the time of admission by the clinicians managing the case. Those reported as having bilateral papilloedema with both bilateral haemorrhages and exudates were classified as grade IV. Patients with bilateral retinopathy with papilloedema and haemorrhages or exudates, or both, but with incomplete criteria for grade IV in both eyes were classified as grade IVa. The criteria for grade III retinopathy were bilateral haemorrhages and exudates when papilloedema was reported as being absent; patients with bilateral retinopathy with no papilloedema who did not have haemorrhages and exudates in both eyes were classified as grade IIIa.

Data on blood pressure, serum urea concentrations, the presence of proteinuria or haematuria on dipstick testing, and whether the patient smoked cigarettes at the time of diagnosis of malignant hypertension were collected. The quality of control of the blood pressure in the months and years after diagnosis was calculated by averaging the readings of blood pressure within each six monthly period of follow up and then averaging all of these means to produce a single figure to provide a picture of the usual blood pressure while receiving treatment. The six monthly means were used to avoid a falsely poor picture of the control of blood pressure when many visits were made to the clinic, while attempts were being made to bring the blood pressure down. Special efforts were made to obtain complete follow up in all cases if necessary by contacting general practitioners and writing to patients who had been discharged. Thus accurate follow up data were available in all but 54 cases. Life table analysis, however, is a technique designed to include lost patients for as long as they are known to be alive. ${ }^{17}$

In view of the different rates of cigarette smoking in men and women and in whites, blacks, and Asians ${ }^{18}$ the patients with malignant and accelerated hypertension were compared, in a separate analysis, with those with nonmalignant hypertension who had attended the blood pressure clinic at this hospital from 1 June 1977; patients were matched for age ( \pm 2 years), sex, and ethnic origin.

Differences in survival rates between groups were analysed statistically by the life table technique of $\mathrm{Cox}^{17}$ using the statistical package for social sciences. ${ }^{19}$

\section{Results}

Two hundred patients with malignant hypertension were analysed, of whom $178(89 \%)$ had essential hypertension. Of the whole series, about half (95) were recorded as having "full house" grade IV retinopathy and 31 had bilateral haemorrhages and bilateral exudates (grade III). A total of 74 patients had incomplete retinal features and were classified as grade IVa or grade IIIa (table I). There were no significant differences in the average age, presenting blood pressure, or frequency of proteinuria or haematuria in the four subgroups. Patients with grade IIIa retinopathy had slightly lower serum urea concentrations and proteinuria was less common, but these trends were not statistically significant.

Information on smoking habits was available in $182(91 \%)$ patients (table II). Cigarette smoking was significantly more common in patients with grades IV and IVa retinopathy compared with control patients with nonmalignant hypertension matched for age, sex, and race. The slight excess of smoking in grades III and IIIa was not statistically significant.

Ninety one patients were known to have died during follow up, and their average duration of follow up until death was 5.25 years; 51 patients were known to be alive at the time of analysis (average follow up 3.5 years) and 54 were lost to follow up (average follow up 3.5 years). From the clinical features at presentation the severity of hypertension did not differ in the four groups, although patients with grade IIIa retinopathy had less renal failure 
and less proteinuria (table I). Analysis of survival rates was in keeping with these risk factors. No differences in survival rate were found in patients with grades IV, IVa, and III retinopathy (figure). The survival rate in the 20 patients with grade IIIa retinopathy was better than that in patients with grade IV retinopathy (Lee Desu statistic: $4 \cdot 4, p<0.05$ ). The average blood pressure at follow up was lower than that in the other groups and they also smoked less; but this factor may not be relevant as in the whole series of 200 patients there was no difference in survival in those who did and those who did not smoke.

Roughly 10 new patients with malignant hypertension were seen in each year, but there was a considerable deficit of cases in the years 1960-4, and in these early patients survival rates were high (table III). The data for these

TABLE III-No of new cases of malignant hypertension seen between 1960 and 1982 in relation to degree of retinopathy and two year survival rates. (Small No of cases for $1960-4$ may be due to inadequate reporting and lost records)

\begin{tabular}{|c|c|c|c|c|c|}
\hline & \multicolumn{5}{|c|}{ Years } \\
\hline & $1960-4$ & $1965-9$ & $1970-4$ & $1975-9$ & $1980-2$ \\
\hline Grades IV and IVa & 18 & 43 & 44 & 30 & 14 \\
\hline Grades III and IIIa & 2 & 10 & 5 & 20 & 14 \\
\hline All patients & 20 & 53 & 49 & 50 & 28 \\
\hline $\begin{array}{l}\% \text { Surviving at two year } \\
\text { follow up }\end{array}$ & 82 & 50 & 47 & 70 & 68 \\
\hline
\end{tabular}

TABLE I-Details of 200 cases of malignant hypertension. (Figures are means (SEM) or \% where stated). Data on proteinuria, haematuria, and smoking habits were missing on some patients

\begin{tabular}{|c|c|c|c|c|c|}
\hline & \multicolumn{5}{|c|}{ Grade of retinopathy } \\
\hline & $\underset{(n=95)}{\text { IV }}$ & $\begin{array}{c}\mathrm{IVa} \\
(\mathrm{n}=54)\end{array}$ & $\underset{(n=31)}{\text { III }}$ & $\begin{array}{c}\text { IIIa } \\
(n=20)\end{array}$ & $\begin{array}{c}\text { Total } \\
(n=200)\end{array}$ \\
\hline \multicolumn{6}{|l|}{ No of patients $(M / F)$ : } \\
\hline White & $48 / 25$ & $30 / 11$ & $18 / 3$ & $7 / 2$ & $103 / 41$ \\
\hline Black & $12 / 3$ & $6 / 3$ & $6 / 3$ & $2 / 1$ & $26 / 10$ \\
\hline Asian (Indian subcontinent) & $5 / 2$ & $3 / 1$ & $1 / 0$ & $7 / 1$ & $16 / 4$ \\
\hline Age (years) & $45 \cdot 9(1 \cdot 2)$ & $50 \cdot 5(1 \cdot 6)$ & $46 \cdot 7(1 \cdot 5)$ & $51 \cdot 6(2 \cdot 5)$ & $47 \cdot 8(0 \cdot 8)$ \\
\hline Presenting systolic blood pressure (mm Hg) & $227 \cdot 8(2 \cdot 7)$ & $227 \cdot 6(3 \cdot 8)$ & $238 \cdot 5(5 \cdot 2)$ & $224 \cdot 9(6 \cdot 7)$ & $229 \cdot 1(2 \cdot 0)$ \\
\hline Presenting diastolic blood pressure $(\mathrm{mm} \mathrm{Hg})$ & $141 \cdot 5(2 \cdot 3)$ & $141 \cdot 7(3.0)$ & $145 \cdot 0(3 \cdot 4)$ & $136 \cdot 4(4 \cdot 0)$ & $141.7(1.5)$ \\
\hline $\begin{array}{l}\text { Proteinuria } \\
\text { Pas }\end{array}$ & $80 / 89(90 \%)$ & $40 / 48(83 \%)$ & $22 / 30(73 \%)$ & $11 / 20(55 \%)$ & $153 / 187(82 \%)$ \\
\hline Haematuria & $24 / 88(27 \%)$ & $8 / 48(17 \%)$ & $6 / 30(20 \%)$ & $4 / 20(20 \%)$ & $42 / 186(24 \%)$ \\
\hline Serum urea $(\mathrm{mmol} / \mathrm{l})$ & $15 \cdot 6(1 \cdot 5)$ & $13 \cdot 1(2 \cdot 6)$ & $18 \cdot 9(2 \cdot 8)$ & $8 \cdot 6(1 \cdot 0)$ & $14 \cdot 7(1 \cdot 1)$ \\
\hline Follow up systolic blood pressure $(\mathrm{mm} \mathrm{Hg})$ & $188 \cdot 4(3 \cdot 2)$ & $185 \cdot 2(3 \cdot 5)$ & $194 \cdot 0(5 \cdot 3)$ & $174 \cdot 8(7 \cdot 3)$ & $187 \cdot 0(2 \cdot 1)$ \\
\hline Follow up diastolic blood pressure (mm Hg) & $116 \cdot 4(1 \cdot 7)$ & $112 \cdot 8(2 \cdot 0)$ & $118 \cdot 7(3 \cdot 4)$ & $106 \cdot 7(3 \cdot 2)$ & $114 \cdot 8(1 \cdot 2)$ \\
\hline Current smokers at presentation & $57 / 86(58 \%)$ & $32 / 48(67 \%)$ & $14 / 28(50 \%)$ & $8 / 20(40 \%)$ & $111 / 182(61 \%)$ \\
\hline Ever smokers & $64 / 86(74 \%)$ & $35 / 48(73 \%)$ & $16 / 28(37 \%)$ & $12 / 20(60 \%)$ & $127 / 182(70 \%)$ \\
\hline
\end{tabular}

Conversion: SI to traditional units: Urea $1 \mathrm{mmol} / / \approx 6.02 \mathrm{mg} / 100 \mathrm{ml}$.

TABLE II-Smoking habits at time of presentation in 182 patients with malignant hypertension when details of smoking were available, compared with control patients with non-malignant hypertension matched for age, sex, and ethnic origin

\begin{tabular}{|c|c|c|c|c|c|}
\hline & Smoker & $\begin{array}{l}\text { Non-smoker } \\
\text { or ex-smoker }\end{array}$ & $\begin{array}{l}\text { No of } \\
\text { cases }\end{array}$ & $\chi^{2}$ & $\mathrm{p}$ Value \\
\hline $\begin{array}{l}\text { Grade IV } \\
\text { Control }\end{array}$ & $\begin{array}{l}57 \\
24\end{array}$ & $\begin{array}{l}29 \\
62\end{array}$ & 86 & $25 \cdot 4$ & $<0.001$ \\
\hline $\begin{array}{l}\text { Grade IVa } \\
\text { Control }\end{array}$ & $\begin{array}{l}32 \\
14\end{array}$ & $\begin{array}{l}16 \\
34\end{array}$ & 48 & $13 \cdot 5$ & $<0.001$ \\
\hline $\begin{array}{l}\text { Grade III } \\
\text { Control }\end{array}$ & $\begin{array}{l}14 \\
10\end{array}$ & $\begin{array}{l}14 \\
18\end{array}$ & 28 & $1 \cdot 2$ & NS \\
\hline $\begin{array}{l}\text { Grade IIIa } \\
\text { Control }\end{array}$ & $\begin{array}{l}8 \\
6\end{array}$ & $\left.\begin{array}{l}12 \\
14\end{array}\right\}$ & 20 & 0.4 & NS \\
\hline
\end{tabular}

first five years were probably incomplete and tended to include more survivors, as some hospital records from that time were lost and patients who died early in the course of their illness may have been omitted from this series. The trends from 1965 onwards were, by contrast, consistent. Life table analyses showed no differences in survival in each five year period, although there may have been a trend for improved rates from 1975 onwards.

\section{Discussion}

This is a retrospective study of malignant hypertension in a district hospital, and although the hospital activity analysis was used to collect data on all admissions, some cases in the early years were evidently missing. The hospital activity analysis system has a measurable error rate, ${ }^{20}$ but this is small for definitive diagnoses like malignant hypertension, although it may be high for non-specific diseases. We are, however, confident that every case from 1 June 1977 was included as all clinicians at the hospital helped to ensure that none were omitted.

Grading of the degree of retinopathy was generally detailed as many patients were admitted from the Birmingham and Midland Eye Hospital, had retinal photography, or were documented in great detail for teaching purposes. From 1977 the retinal classifica-

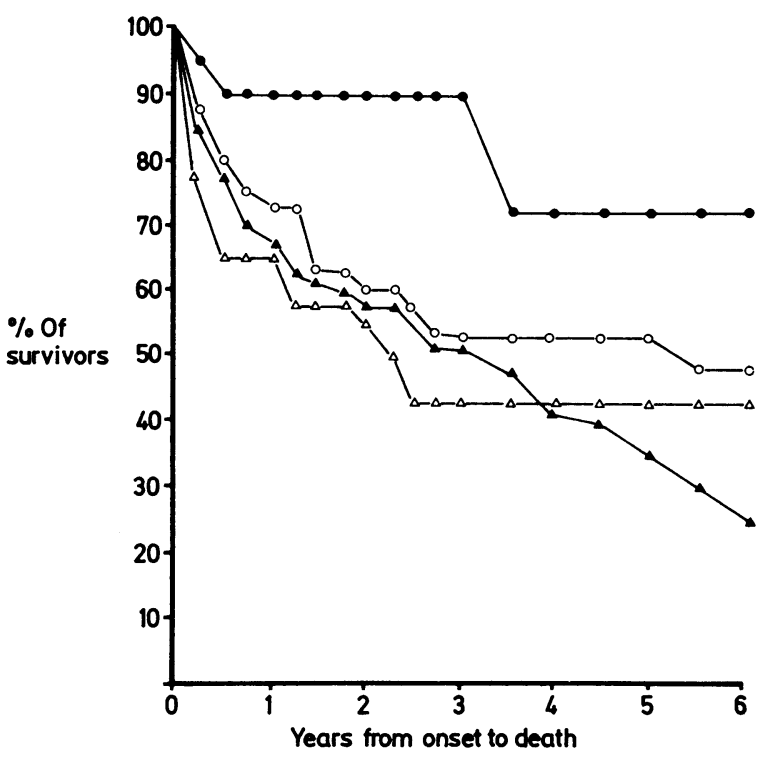

Life table analysis of survival in $\mathbf{2 0 0}$ consecutive patients with grades IV $(\Delta-\Delta)$, IVa $(\bigcirc-O)$, III $(\triangle-\Delta)$, and IIIa $(-)$ ) hypertensive retinopathy. Overall Lee Desu statistic not significant, but survival was greater in patients with grade IIIa compared with grade IV and III $(p<0.05)$

tion was performed mainly by one clinician. Retinoscopic classification is less reliable than angiography or fundal mapping, which weakens the analysis, but one of our strengths was that we included all patients who were admitted, many of whom were acutely ill and died before more accurate angiography was feasible.

In this series of patients cigarette smoking was commoner than in control patients with non-malignant hypertension, which confirmed our observations in a previous, smaller analysis. ${ }^{13}$ The malignant cases dated back to 1960 , however, while the nonmalignant cases dated from 1977. Patients with malignant hypertension could not be compared with those with non-malignant 
hypertension admitted at the same time because the latter tended to be admitted for other reasons, including vascular complications of hypertension, which might be related to smoking. The lack of association between hypertension and cigarette smoking is well documented, ${ }^{21}$ but inclusion of control cases with end organ damage might have shown a different trend. The small reduction in cigarette smoking in the United Kingdom over the past 10 years cannot account for the observed excess of smoking in patients with malignant hypertension, which has been confirmed elsewhere..$^{1416}$ We were unable to confirm the link of smoking with grades III and IIIa retinopathy, although smoking was slightly more common than in control patients. Other authors usually combined their patients with grade III and IV retinopathy in similar analyses.

The prognosis of malignant hypertension, if left untreated, is worse than any form of cancer, with up to $90 \%$ of patients dead in one year. ${ }^{12}$ Controlling blood pressure prolongs life, ${ }^{22}$ and long term follow up studies have reported a dramatic reduction in mortality. ${ }^{10}$ The results of treatment in our patients were disappointing, but this may be because our cases dated back to 1960, when effective antihypertensive treatment was not so enthusiastically prescribed. Furthermore, this series includes all patients seen in a district general hospital, some of whom were acutely ill and died within hours or days of admission.

The Keith Wagener classification with its gradation of retinopathy from one to four suggests a gradation of risk that is not borne out by our findings. The clinical features of hypertension in patients with grades III and IV retinopathy are similar and quite distinct from those seen in patients without retinopathy. Although the severity of hypertension and quality of control of blood pressure with antihypertensive drugs are both potent predictors of risk, ${ }^{23}$ malignant hypertension seems to carry a particularly bad prognosis, probably related to renal damage due to fibrinoid necrosis of intrarenal arterioles. If control of blood pressure had been better mortality might have been further reduced. The Keith Wagener classification of hypertensive retinopathy, however, seems particularly unhelpful as grade III and IV do not differ, so we suggest that is should be abandoned. Malignant and accelerated hypertension are one and the same disease, which should be regarded as a medical emergency requiring accurate long term control of blood pressure.
JMW was supported by a grant from ICI Pharmaceuticals and MB by the DHSS computer clinics project. We thank Dr J Mackinnon for providing data from the department of cardiology, Dr A Paton for access to his retinal photography archive, Mr Roy Haynes for access to the Hospital Activity Analysis Archive, Mrs V L Stewart for secretarial help, and Mrs E Thomas for access to medical records.

\section{References}

1 Pickering GW. High blood pressure. 2nd ed. London: J \& A Churchill, 1962.

2 Beevers DG, Brown JJ, Ferriss JB, et al. Renal abnormalities and vascular complications in primary hyperaldosteronism. Evidence of tertiary hyperaldosteronism. Q $\mathcal{f}$ Med 1976;45: 401-10. 3 Schleer LR, Jones BD. Malignant nephrosclerosis in women post partum. FAMA 1967;201:
106-8.

4 Kincaid-Smith P. Vascular changes in homotransplants. BrMed $\mathcal{F}$ 1964;i:178-9.

5 Allison PR, Blechan N, Brown W, Pickering GW, Robb-Smith AHT, Russell RP. The production and resolution of hypertensive vascular disease in the rabbit. Clin Sci 1967;33:39-51. 6 Koffler D, Paronetto F. Fibrinogen deposition in acute renal failure. Am f Pathol 1966;49:303-40.

7 Gifford RW. Management and treatment of malignant hypertension and hypertensive emergencies. In: Genest J, Koiw E, Kuchel O, eds. Hypertension. New York: McGraw-Hill, 1977:1024-38.

8 Woods JW. Malignant hypertension: clinical recognition and management. Cardiovasc Clin 1978;9:311-20

9 World Health Organisation. Report of a WHO expert committee. Arterial hypertension. WHO Tech Rep Ser 1978; No 628.

10 Gudbrandsson T, Hansson L, Herlitz H, Andreu L. Malignant hypertension: improving prognosis in a rare disease. Acta Med Scand 1979;206:495-9.

11 Dollery CT, Bulpitt CJ. Factors affecting the care of patients with malignant hypertension. $\mathcal{F} R$ Coll Physicians Lond 1979;13:95-7.

12 Keith NM, Wagener HP, Barker NW. Some different types of essential hypertension: their course and prognosis. Am f Med Sci 1939;196:332-43.

13 Bloxham CA, Beevers DG, Walker JM. Malignant hypertension and cigarette smoking. Br Med $\mathcal{J}$ 1979; i:581-3.

14 Isles C, Brown JJ, Cumming AMM, et al. Excess smoking in malignant hypertension. Br Med $\mathcal{J}$ 1979;i:579-81.

15 Elliott JM, Simpson FO. Cigarettes and accelerated hypertension. N Z F Med 1980;91:447-9.

16 Tuomilehto J, Elo J, Nissinen A. Smoking among patients with malignant hypertension. BrMed $\mathcal{J}$ 1982;284:1086.

17 Cox DR. Regression models and life tables. Foumal of the Royal Statistical Society 1972;32. $187-220$.

18 Jackson SHD, Beevers DG, Cruickshank JK, Bannan LT. Ethnic differences in peak expiratory flow rate in Birmingham factory workers. Postgrad Med F 1983;59:671-3.

19 Hull CH, Nie NH. SPSS update 7-9. New York: McGraw-Hill, 1981:205-19.

20 Scott-Samuel A. Accuracy of data based on hospital discharge diagnoses. Br Med $\mathcal{F}$ 1978;i:990.

21 Ballantyne D, Devine BL, Fife R. Interrelation of age, obesity, cigarette smoking and blood pressure in hypertensive patients. Clinical Science and Molecular Medicine 1978;55:333-6s.

22 Harrington $M$, Kincaid-Smith $P$, McMichael J. Results of treatment in malignant hypertension. A seven year experience in 94 cases. $B r$ Med f 1959;ii:969-80.

23 Beevers DG, Johnston J, Devine BL, Dunn FG, Larkin H, Titterington DM. Relation between prognosis and the blood pressure before and during treatment of hypertensive patients. Clinical Science and Molecular Medicine 1978;55:333-6s.

(Accepted 6 November 1985)

\section{SHORT REPORTS}

\section{Diclofenac sodium versus pethidine in acute renal colic}

Experimental work suggests that prostaglandins play an important part in producing pain in renal colic, ${ }^{12}$ and studies have suggested that antiprostaglandins may be of value in the management of this condition. ${ }^{3} \mathrm{We}$ designed this trial to compare the efficacy of and tolerance to diclofenac sodium, a potent inhibitor of prostaglandin synthetase, with those of the commonly prescribed narcotic pethidine in the management of acute renal colic.

\section{Patients, methods, and results}

Patients presenting to the accident and emergency department with severe pain and thought to have acute renal colic were entered into this double blind study, being randomised to receive an intramuscular injection of either pethidine $100 \mathrm{mg}$ or diclofenac sodium $75 \mathrm{mg}$. We excluded those already taking non-steroidal antiinflammatory agents; those with a history of allergies, asthma, peptic ulceration, or renal insufficiency; and those who had been given strong analgesics by their general practitioner before their admission.

On entering the study the patient assessed his pain on a scale from 0 to $5(0=$ no pain at all; $5=$ the most severe pain imaginable). The pain score was recorded every 15 minutes for the next hour and then at hourly intervals. Treatment was regarded as successful if the pain score improved by three points or more. A second injection of the same drug was offered after 30 minutes if the first had not been successful or if pain had returned. If pain persisted at one hour or returned thereafter patients were given pethidine $100 \mathrm{mg}$ intramuscularly. Side effects attributable to the treatment were recorded by the patient or the medical staff. An urgent intravenous urogram was obtained in all patients and was normal in 12 , who were therefore withdrawn from the study.

Altogether 58 patients were evaluated ( 41 men, 17 women), their ages ranging from 19 to 85 years (mean 46 years). Thirty received diclofenac sodium and 28 pethidine. Both groups were comparable for weight, sex, age, and the site and size of the stone. Of the 30 patients who received diclofenac sodium, $28(93 \%)$ obtained satisfactory relief of pain after a single injection, compared with only 18 of the $28(65 \%)$ who received pethidine ( $p<0.05$, Fisher's exact test) (table).

Pain relief after single injection (figures are numbers of patients)

\begin{tabular}{lccc}
\hline & $\begin{array}{c}\text { Satisfactory } \\
\text { ( } \geqslant 3 \text { point improvement) }\end{array}$ & $\begin{array}{c}\text { Mild } \\
(1-2 \text { point improvement })\end{array}$ & None \\
\hline $\begin{array}{l}\text { Diclofenac sodium } \\
\text { Pethidine }\end{array}$ & 28 & 2 & 5
\end{tabular}

Thus 12 patients required a second injection 30 minutes later. All had severe pain at that time, though seven reported transient moderate relief of pain after the first injection. No patient required further analgesia at one hour.

Side effects occurred in 14 patients receiving pethidine $(50 \%)$ but in only five receiving diclofenac sodium (17\%). They included nausea, vomiting, drowsiness, and blurred vision but were transient and not severe. 